\title{
Health Assessment of Newborns - A Community Based Study in Jharsuguda District of Odisha, India
}

\author{
Sahu $\mathbf{S}^{\mathbf{1}}$, Lenka $\mathbf{C}^{\mathbf{2}}$ \\ ${ }^{1}$ Belpahar H.S.S Belpahar, Jharsuguda, Odisha, India \\ ${ }^{2}$ P.G. Department of Home Science, Sambalpur University, Odisha, India-768019 \\ ${ }^{1}$ Suravi.smart@gmail.com
}

\begin{abstract}
Newborns of today are tomorrow's citizens; thus, it is crucial to ensure good health for newborns. Today child's health ponders the health of the future generation, and it assist in forecasting future public health problems for families, communities as well as the healthcare system of the nation. The objective of the present research is to assess the nutritional and health status of the newborns with the help of Birth weight BMI, PI CAN score. Lakhanpur and Jharsuguda Block of Jharsuguda district of Odisha, India was selected as study area and purposive sampling method was followed. 300 women in the third trimester of pregnancy till their delivery were selected from the total population. The research concluded that, assessment of health status of newborns by birth weight, PI, BMI and CAN score revealed that more percentage of malnourished newborns identify by CAN score i.e. $44.67 \%$ followed by birth weight i.e $.40 .66 \%$ whereas by BMI it was $29 \%$ by PI it was $15.33 \%$. Thus it can be concluded that CAN score is the best tool to identify malnourished neonates who may be identified as well-nourished neonates by other tools.
\end{abstract}

Keyword: Newborn's health, Birth weight, BMI, PI, CAN score

\section{Introduction}

Newborns of today are tomorrow's citizens; thus, it is crucial to ensure good health for newborns. The health of newborns plays a significant role in the development of a nation. The first 28 days of life constitutes the most critical stage of life. In this period of life, the foundation stone is laid for physical, mental and social development. Today child's health ponders the health of the future generation, and it assist in forecasting future public health problems for families, communities as well as the healthcare system of the nation [1]. As newborns are descendents of next generation, thus making them sound and healthy is call of the hour. Healthy newborns ensure healthy adults who are key to healthy economic growth and reinforcement of the nation.

According to the UNICEF report, every year, 20 lacs babies die globally within the neonatal period. The neonatal mortality rate is 25.4 in India, India has 12 th ranked among 52 lower-middle-income nation in newborn mortality [2]. This report also said that India is the only one major nation in the world, which has the higher mortality among girls than boys. While Kerala and Goa have $10 \%$ of neonatal mortality, whereas Bihar, Uttarakhand has $44 \%$. Uttar Pradesh, Madhya Pradesh, Rajasthan stands at 57\%.It was globally estimated that $15 \%$ 
to $20 \%$ of newborns were born with low birth weight, and it represented more than 20 million births in a year.The WHO goal is to achieve a $30 \%$ reduction in low birth weight among newborns by 2025 . The reduction of infant mortality is an area concern for governments across the globe[3].

According to SRS report 2017, I60\% of the infant death occurs during the first 28 days of life, while about 9 percent died within the first 24 hours ( 1 day) of birth due to asphyxia (insufficient oxygen supply), prematurity, low birth weight, respiratory infection, diarrhoea and malnutrition [4]. It was also found that the infant mortality rate is higher in low socioeconomic groups who live in backward tribal districts [5]. According to the "Annual Health Survey (2012-13)", the Child Mortality Rate of Jharsuguda district was 42, and the Maternal Mortality Rate was 234 whereas NMR is 34. The district average of Institutional delivery in percentage is 99 , and the immunization status of children below five years is 83.2 $\%[6]$.

\section{Objective}

The objective of the study is to assess the nutritional and health status of the newborns with the help of Birth weight BMI, PI CAN score.

\section{Literature review}

Singhal et al,. (2012) conducted an examination CAN score to the detection of fetal malnutrition by at birth and its association with different methods of determining prenatal growth and found that to CAN score recognized $17.5 \%(\mathrm{n}=35)$ malnourished babies and $82.5 \%(\mathrm{n}=165)$ of children also fed by keeping the cut-off estimation of $<25.8 \%$ of AGA children and $76.8 \%$ of SGA babies were seen as very much supported on contrasting weight for growth age and CAN score. 8\% of babies were found to have FM utilizing PI yet by applying CAN score just 10 children were found to have FM [10].

Soundarya et al., (2012) made an examination on comparative analysis of fetal malnutrition by anthropometry and CAN score and found that the incidence of FM was $24 \%$. Infants recognized malnourished by $\mathrm{PI}, \mathrm{BMI}, \mathrm{MAC} / \mathrm{HC}$ were assessed by $\mathrm{CAN}$ score and the noteworthy number of them 31/78 in PI, 60/121 in BMI, 51/81 in MAC/HC were discovered all around sustained [9].

\section{Methodology}

For the present study, Lakhanpur and Jharsuguda Block of Jharsuguda district of Odisha was selected as a study area. 957 Anganwadi centers at Jharsuguda district out of the 16 numbers of Anganwadi centers of Lakanpur block and 12 Anganwadi centers of Jharsuguda Block were selected randomly for the present study. Considering the different literature and keeping objectives in the mind exploratory cum descriptive research was most adopted for the present study. For the present study, the purposive sampling method was followed. 300 women in the third trimester of pregnancy till their delivery and their babies were selected from the total population. 


\section{Study criteria:}

- Inclusion Criteria:

1. Permanent resident of the study area
2. Live birth babies
3. Singleton babies
4. Hospital delivery

\section{- $\quad$ Exclusion criteria}

1. Went to the maternal house for delivery.
2. Stillbirths
3. Twin gestation
4. Home delivery

\section{Anthropometric measurements of newborns:}

For the assessment of the nutritional status of the newborn's weight, crown heel length, head, chest, and mid-arm circumference were taken with standard instruments like weighing machine,measuring tape, and infantometer. Weight and height weremeasured to nearest 0.1 $\mathrm{kg}$ and $0.1 \mathrm{~cm}$ respectively with minimal cloth and shoes.

- Weight: Weight of the newborn was recorded immediately after delivery.

- Height or Length: Length is recorded in $\mathrm{cm}$ after delivery with the help of an infantometer.

- Chest Circumference: The chest circumference of the newborn was measured by putting the measuring tape horizontally around the chest just across the nipple. The lowest measurement recorded during the normal breathing process.

- Head Circumference: The head circumference of the newborn was measured in $\mathrm{cm}$ with the help of a flexible metal measuring tape. Then the tape was wrapped snugly around the widest possible circumference from the most prominent part of the forehead (often 1-2 finger above the eyebrow) around to the widest part of the back of the head and it was remeasured three times and took the largest number.

- Mid arm circumference: The Mid arm circumference of the newborn was measured in $\mathrm{cm}$ with the help of measuring tape. MUAC is the circumference of the left upper arm and is measured at the mid-point between the tips of the shoulder and elbow. To measure MUAC: bend the left arm, find and mark with a pen the olecranon process and chromium, then mark the mid-point between these two marks. With the arm hanging straight down, wrap a MUAC tape around the arm at the mid-point mark. At last, measure to the nearest $1 \mathrm{~mm}$.

\section{Ponderal Index (PI):}

Ponderal Index (PI) is a measure of the leanness of a person calculated as a relationship between mass and height. It was first proposed in 1921 by Swiss Physician Fritz Rohrer so it is also known as Rohrer's index.The PI formula is given below-

Ponderal Index $(\mathrm{PI})=$ Weight $(\mathrm{Gms}) \times 100 /$ length $(\mathrm{Cms})^{3}$

Ponderal Index (PI) of less than $2.2 \mathrm{gm} / \mathrm{cm}^{3}$ was considered as an index of malnutrition.

\section{Body Mass Index (BMI) of newborns:}

Body mass index (BMI) is a calculation used to assess the body weight according to height. The BMI formula is given below-

Body mass index $(\mathrm{BMI})=$ weight $(\mathrm{Kg}) /$ length $(\mathrm{m})^{2}$

A cut off value of $11.20 \mathrm{~kg} / \mathrm{m}^{2}$ was considered as malnutrition.

Clinical assessment of newborns by "CAN score": 
The clinical assessment of newborns was assessed by clinical assessment of nutrition score popularly termed a "CAN Score" devised by Metcoff J (1994) [7]. The score was used from the examination of clinical signs on nine regions of the body viz. hair, cheeks, neck, arms, chest, skin of the abdominal wall, back, buttocks and leg.Depending upon the grade of development of clinical sign CAN Score was awarded for each region ranging from a minimum of 1 to a maximum of 4 as suggested by Metcoff. A score of 4 denotes "wellnourished" and a score of 1 denotes evidence of malnutrition. A score of 2 or 3 indicates a degree of improvement in the nutritional status compared to the score of one. The highest possible rating of CAN Score is 36 and the lowest possible is 9 for the nine regions of the body collectively.

\section{Result and Discussion}

\section{Birth weight of newborns}

Table 1. Distribution of newborns on the basis of birth weight

\begin{tabular}{lll}
\hline Birth weight & Number & Percentages \\
\hline Below $1.5 \mathrm{~kg}(\mathrm{VLBW})$ & 3 & 1.00 \\
1.5 to $2 \mathrm{~kg}(\mathrm{LBW})$ & 16 & 5.33 \\
2 to $2.5 \mathrm{~kg}(\mathrm{LBW})$ & 103 & 34.33 \\
2.5 t0 $3 \mathrm{~kg}(\mathrm{NBW})$ & 97 & 32.33 \\
3 to $3.5 \mathrm{~kg}(\mathrm{NBW})$ & 70 & 23.33 \\
Above $3.5 \mathrm{~kg}(\mathrm{NBW})$ & 11 & 3.68 \\
Total & 300 & 100 \\
\hline
\end{tabular}

Table 1 reveals that the distribution of newborns according to their birth weight and the prevalence of low birth weight among newborns was $40.66 \%$. On further analysis, it was observed that the majority (59.34\%) newborns had normal birth weight (NBW) followed by $39.66 \%$ newborns belonged to low birth weight (LBW) category whereas only $1 \%$ newborns found under very low birth weight (VLBW) category. According to NFHS-3 prevalence of low birth weight in rural India is $22.1 \%$ but in the present research, the percentage of LBW was found to be more by $17.56 \%$ which is a matter of concern. Agrawal and Sharma (2017) investigated the incidence of LBW and found that the majority of $41 \%$ newborns had 2.5 to $3.49 \mathrm{~kg}$ birth weight [8].

\section{I.2. Health status of newborns according to CAN Score}

Table 2. Distribution of newborns on the basis of CAN score

\begin{tabular}{lll}
\hline Can score & Number & Percentages \\
\hline Malnourished & 134 & 44.67 \\
Well-nourished & 166 & 55.33 \\
Total & 300 & 100 \\
\hline
\end{tabular}

Table 2 indicates that the prevalence of malnutrition among newborns according to CAN score. It was observed that $44.67 \%$ of newborns were malnourished whereas $55.33 \%$ 
were well-nourished. The incidence of malnutrition was found to be $24 \%$ by Soundarya et $a l$.. (2012) [9]. Singhal et al., (2012) also identified 17.5\% malnourished neonates and $82.5 \%$ of babies as well-nourished with the help of CAN Score in their studies [10].

\section{Health status of newborns according to Ponderal index}

Table 3. Distribution of newborns on the basis of the ponderal index

\begin{tabular}{lll}
\hline Ponderal index & Number & Percentages \\
\hline Malnourished & 46 & 15.33 \\
Well-nourished & 254 & 84.67 \\
Total & 300 & 100 \\
\hline
\end{tabular}

Table 3 indicates that the prevalence of malnutrition among newborns according to PI. It was observed that $15.33 \%$ of newborns were malnourished whereas $84.67 \%$ were wellnourished. Singhal et al., (2012) also identified $8 \%$ malnourished neonates as per PI [10] whereas Soundarya et al., (2012) also identified 26\% malnourished neonates and $74 \%$ babies well-nourished with the help of PI in their studies [9].

\section{Health status of newborns according to BMI}

Table 4. Distribution of newborns on the basis of BMI

\begin{tabular}{lll}
\hline BMI of newborn & Number & Percentages \\
\hline Underweight & 87 & 29 \\
Normal weight & 213 & 71 \\
Total & 300 & 100 \\
\hline
\end{tabular}

Table 4 shows that the prevalence of underweight was $29 \%$ among newborns according to BMI whereas $71 \%$ of newborns were normal at birth. Incidence of malnutrition was found to be $24 \%$ by Soundarya, et al., (2012) and also identified $40.33 \%$ underweight neonates and 59.66\% well-nourished with the help of BMI of newborns in their studies [9].

\section{Comparative Statement of Nutritional status of newborns}

Table 5. Nutritional status of newborns in comparison to ICMR value

\begin{tabular}{|c|c|c|c|c|c|c|c|c|}
\hline Variable & & $\begin{array}{l}\text { Normal } \\
\text { Body } \\
\text { measureme } \\
\text { nt value } \\
\text { (ICMR) }\end{array}$ & $\begin{array}{l}\text { Actu } \\
\text { al } \\
\text { Mea } \\
\text { n } \\
\pm \text { S.D. }\end{array}$ & $\begin{array}{l}\text { Kurtos } \\
\text { is }\end{array}$ & $\begin{array}{l}\text { Skewne } \\
\text { ss }\end{array}$ & $\begin{array}{l}\text { Rang } \\
\text { e }\end{array}$ & Minimu & $\begin{array}{l}\text { Maximu } \\
\text { m }\end{array}$ \\
\hline $\begin{array}{l}\text { Birth } \\
\text { (Kg) }\end{array}$ & Weight & $2.5-4.3$ & $\begin{array}{l}2.71 \\
\pm \\
0.49\end{array}$ & -0.15 & -0.01 & 2.87 & 1.125 & 4 \\
\hline
\end{tabular}




\begin{tabular}{|c|c|c|c|c|c|c|c|}
\hline $\begin{array}{l}\text { Crown Heel } \\
\text { Length (cms) }\end{array}$ & $46.3-53.4$ & $\begin{array}{l}48.05 \\
\pm \\
2.93\end{array}$ & -0.84 & 0.38 & 12.9 & 42.8 & 55.7 \\
\hline $\begin{array}{l}\text { Chest } \\
\text { Circumference(c } \\
\text { ms) }\end{array}$ & $30.5-33$ & $\begin{array}{l}32.12 \\
\pm \\
1.54\end{array}$ & -0.78 & 0.46 & 6.5 & 29.4 & 35.9 \\
\hline $\begin{array}{l}\text { Head } \\
\text { Circumference } \\
\text { (cms) }\end{array}$ & $33.9-34.3$ & $\begin{array}{l}34.16 \\
\pm \\
1.49\end{array}$ & -0.96 & 0.33 & 6.5 & 31.5 & 38 \\
\hline $\begin{array}{l}\text { Arm } \\
\text { Circumference } \\
\text { (cms) }\end{array}$ & 9- 10.76 & $\begin{array}{l}9.67 \\
\pm \\
0.46\end{array}$ & -0.40 & -0.32 & 2 & 8.5 & 10.5 \\
\hline
\end{tabular}

Table 5 indicates nutritional status of newborns. The mean birth weight, crown heel length, chest circumference, head circumference, and arm circumference was found to be $2.71 \pm 0.49,48.05 \pm 2.93,32.12 \pm 1.54,34.16 \pm 1.49$ and $9.67 \pm 0.46$ respectively. The minimum weight of newborns was $1.125 \mathrm{~kg}$. and the maximum was $4 \mathrm{k} . \mathrm{g}$. with 2.87 range, 0.15 kurtosis, and -0.01skewness. The minimum crown heel length of newborns was $42.8 \mathrm{~cm}$. and the maximum was $55.7 \mathrm{~cm}$ with $12.9,-0.84$ and 0.38 of range, kurtosis, and skewness respectively. The minimum chest circumference of newborns was $29.4 \mathrm{~cm}$ and the maximum was $35.9 \mathrm{~cm}$. with 6.5 range, -0.78 kurtosis, and 0.46 skewness. The minimum head Circumference of newborns was $31.5 \mathrm{~cm}$ and the maximum was $38 \mathrm{~cm}$. with 6.5 range, -0.96 kurtosis, and 0.33skewness. The minimum arm circumference of newborns was $8.5 \mathrm{~cm}$. and maximum $10.5 \mathrm{~cm}$ with 2,-0.40 and -0.32 range, kurtosis, and skewness respectively. Similar findings was also obtained by Kabir et al., (2014) that, the mean weight, length, MUAC, head circumference, and chest circumference was found to be 2.44(0.42), 46.43(2.41), 9.31(0.84), 32.36(1.63) and 30.40(2.09) respectively [13]. The mean birth weight, crown heel length, chest circumference, head circumference, and arm circumference of newborns was found to be normal in comparison to ICMR value.

\section{Correlation between birth weight and other body measurements of newborns Table 6. Correlation between birth weight and other body measurements of newborns}

\begin{tabular}{lllll}
\hline Model & $\mathbf{R}$ & R Square & F & Sig. \\
\hline 1 & $.942^{\mathrm{a}}$ & .887 & 576.856 & $.000^{\mathrm{b}}$ \\
\hline
\end{tabular}

a. Dependent Variable: birth weight

b. Predictors: (Constant), arm circumference, chest circumference, Crown heel length, head circumference

From Table .6, it was observed that R2 (coefficient of determination) is 0.887 . It indicates that $88.7 \%$ of the variation in the birth weight of new-borns can be explained by four independent variables i.e. other body measurements of new-borns. However, with $\mathrm{F}=$ 576.856 and value is 0.000 this indicates that the regression model is statistically significant. So the result of the present model explains that the birth weight of new-borns is affected by $85.5 \%$ by other body measurements of new-borns. 


\section{Birth weight and body measurement of newborns}

Table 7. Regression output of birth weight and body measurement of newborns

\begin{tabular}{|c|c|c|c|c|c|c|}
\hline \multirow{2}{*}{\multicolumn{2}{|c|}{ Model }} & \multicolumn{2}{|c|}{$\begin{array}{l}\text { Unstandardized } \\
\text { Coefficients }\end{array}$} & \multirow{2}{*}{$\begin{array}{l}\text { Standardized } \\
\text { Coefficients } \\
\text { Beta }\end{array}$} & \multirow[t]{2}{*}{$\mathbf{T}$} & \multirow[t]{2}{*}{ Sig. } \\
\hline & & $\mathrm{B}$ & Std. Error & & & \\
\hline \multirow[t]{5}{*}{1} & (Constant) & -8.393 & .413 & & -20.344 & .000 \\
\hline & $\begin{array}{ll}\text { Crown } & \text { heel } \\
\text { length } & \end{array}$ & -.059 & .018 & -.348 & -3.202 & .002 \\
\hline & $\begin{array}{l}\text { Chest } \\
\text { circumference }\end{array}$ & .059 & .028 & .184 & 2.130 & .034 \\
\hline & $\begin{array}{l}\text { Head } \\
\text { circumference }\end{array}$ & .126 & .052 & .382 & 2.444 & .015 \\
\hline & $\begin{array}{l}\text { Arm } \\
\text { Circumference }\end{array}$ & .799 & .039 & .748 & 20.663 & .000 \\
\hline
\end{tabular}

From Table 7 it was observed that birth weight and other body measurements of newborns were statistically significant such as crown heel length, chest circumference, head circumference, and arm circumference with values of 0.002, 0.034, 0.015 and 0.000 respectively, which are less than 0.05 (significant). From the regression model can be written as follow:

Birth weight of newborns $=-8.393$ (Birth weight of newborns $)+-.059$ (Crown heel length $)+$ 0.059 (Chest circumference) +0.126 (Head circumference) +0.799 (Arm Circumference)

Thus, there was a strong correlation between birth weight and arm circumference, chest circumference, crown heel length, head circumference of newborns were highly significant. It was clear from the above Table that when the birth weight of newborns increases, the other body measurement also increases.

\section{Health condition of newborns}

Table 8. Distribution of newborns according to their health condition

\begin{tabular}{lll}
\hline Health Condition & No & Percentage \\
\hline & 281 & 93.66 \\
Normal & & \\
Abnormal & 19 & 6.33 \\
\hline
\end{tabular}

Table 8 indicate the health condition of the newborns. Most of the babies (93.66\%) were born healthy whereas $6.33 \%$ of newborns had some health complications. 


\section{Health complication of newborns found during birth \\ Table 9. Distribution of newborns on the basis of health complication found during birth}

\begin{tabular}{|c|c|c|}
\hline $\begin{array}{l}\text { Complications } \\
\text { among newborns }\end{array}$ & No & Percentage \\
\hline Jaundice & 8 & 42.11 \\
\hline Infection & 3 & 15.79 \\
\hline NICU experience & 8 & 42.11 \\
\hline
\end{tabular}

*19 numbers of respondents suffering from the health complication

Several unexpected medical issues can arise during labour or after birth with newborns. Table 9 indicates the distribution of respondents based on their health complications found during birth. In this study out of 19 numbers of newborns $42.11 \%$ were suffering from jaundice, $36.84 \%$ were suffering from infection whereas the majority of newborns had NICU experience. According to WHO, more number $(75 \%)$ of all newborns mortality occur during the first 7 days of life, and about 1 million neonates die within the first days of life. Intrapartum-related complications i.e. lack of breathing at birth or birth asphyxia, Preterm birth, and birth defects infections are found significant causes neonatal mortality in year 2017. Sankar et al., (2016) found in their study $20.8 \%$ newborns were suffering from severe infection [11] whereas Sharma et al., (2016) found in their study severe infection (22\%) major causes of neonatal death [12].

\section{Conclusion}

There was a significant statistical correlation found between birth weight and crown heel length, chest, arm, head circumference of newborns. The linear regression model also proves that the other body measurement parameters affected with the increase and decrease of birth weight of newborns such as crown heel length, chest, arm, head circumference of newborns and it was statistically highly significant. Information on the health condition of newborns shows that most of the babies (93.66\%) were born healthy whereas $6.33 \%$ had some complications and out of 19 numbers of newborns, more newborns i.e. $42.11 \%$ suffering from jaundice. Assessment of health status of newborns by birth weight, PI, BMI and CAN score revealed that more percentage of malnourished newborns identify by CAN score i.e. $44.67 \%$ followed by birth weight i.e $.40 .66 \%$ whereas by BMI it was $29 \%$ by PI it was $15.33 \%$. Thus it can be concluded that CAN score is the best tool to identify malnourished neonates who may be identified as well-nourished neonates by other tools.

Short term training programmes, workshops, and training programmes should be organized by the government and voluntary organization for the women as well as family members for adequate antenatal care, maternal nutrition and effective management of health complications of mothers and newborns. 


\section{Acknowledgement}

I would like to thank Dr.Chandrashree Lenka, H.O.D, P.G. Department of Home Science, Sambalpur University for her guidance to prepare the paper.

Funding: No funding sources

Conflict of interest: None declared

\section{REFERENCES}

[1]. Maternal-infant-and-child-health. 2020. Retrieved from the website (https://www.healthypeople.gov) on June 03th , 2020.

[2]. UNICEF. Newborn and child health (2017) Retrieved from the website (https:// www.unicef.org/india/what-we-do/newborn-and-child-health) on January 28th 2019.

[3].World health organization. 2014. Retrieved from website (https:// www.euro.who.int/en/health-topics/disease-prevention/nutrition/a-healthy-lifestyle/bodymass-index-bmi) on September 28th 2019.

[4]. Indian's infant mortality. SRS. 2017. Retrieved from the website the website (www.indianspend.com) on September 25th 2018.

[5]. Government of Odisha. 2019. Infant mortality rate mission-2017. Retrieved from the website (www. health.odisha.gov.in /imr-mission.asp) on November 6th, 2019.

[6]. Maternal health programme (Annual Report 2013-14) Retrieved from the website https://main.mohfw.gov.in/sites/default/files/Chapter415.pdf) on April 1st 2019.

[7]. Metcoff, J. (1994). Clinical assessment of health nutritional status at birth: fetal malnutrition.

[8]Agarwal A, Sharma V. (2017). To Study the maternal factors which determine the low birth weight babies. Pediatric Review. International Journal of Pediatric Research, 4(01), pp. 8-13.

[9]. Soundarya, M., Basavaprabhu, A., Raghuveera, K., Baliga, B., \& Shivanagaraja, B. (2012). Comparative Assessment of Fetal Malnutrition by Anthropometry and CAN Score. Iranian Journal of Pediatrics, 22(1),pp. 70-76.

[10]. Singhal, V., Agal, P., \& Kamath, N. (2012). Detection of Fetal Malnutrition by CAN Score at Birth and its Comparison with other Methods of Determining Intrauterine Growth. Indian Journal of Clinical Practice. 22(11) pp. 576-582.

[11]. Sankar, M. J., Neogi, S. B., Sharma, J., Chauhan, M., Srivastava, R., Prabhakar, P. K., Paul, V. K. (2016). State of newborn health in India. Journal of Perinatology, 36(S3), pp. S3S8. https://doi.org/10.1038/jp.2016.183.

[12]. Sharma, M., \& Mishra, S., (2015) .Maternal risk factors for low birth weight infants: a hospital based study in lucknow. Journal of medical science and clinical research, 03(03), pp. 4761-4769.

[13]. Kabir, A., Merrill, R. D., Shamim A.A., Klemn,R. W., Labrique, A.B., Christian P, West Jr K.P., Nasser, M.,(2014). Canonical Correlation Analysis of Infant's Size at Birth and Maternal Factors: A Study in Rural Northwest Bangladesh. PLoS ONE. 9(4), e94243. doi:10.1371/journal.pone.00942439. 